\title{
Eine einfache mit Luft betriebene Wasserpumpe für die Überwindung größerer Niveau-Unterschiede
}

\author{
FRIEDRICH KRÜGER \\ Biologische Anstalt Helgoland, Zentrale, Hamburg-Altona
}

\begin{abstract}
A simple air driven water pump for overcoming larger level differences. A modification of the well-known air driven water pump is described. Suitable tube diameter (about $5 \mathrm{~mm}$ ) and location of air entry well above the lower tube end (compensation for the recoil effect) significantly increase the pumps capacity to overcome greater differences in water levels.
\end{abstract}

\section{EINLEITUNG}

Im Verlauf experimenteller Untersuchungen an dem Polychaeten Arenicola marina ergab sich die Notwendigkeit, mit einer einfachen Vorrichtung Versuchslösungen in einer Apparatur zirkulieren zu lassen. Die Lösungen mußten von der Stelle, an der sie aus der Apparatur austraten, um etwa $80 \mathrm{~cm}$ zum Eingang des Apparates gehoben werden. Es hätte zwar die Möglichkeit bestanden, diese Funktion einer elektrisch betriebenen Pumpe zu überlassen, aber - abgesehen von dem größeren apparativen Aufwand - läuft man dabei Gefahr, daß die Versuchslösungen mit nicht ganz inerten Materialien in Berührung kommen.

Unter diesen Umständen erschien mir eine mit Luft betriebene Pumpe, die ganz aus Glas oder geeigneten Kunststoffen - zum Beispiel Trovidur - hergestellt werden kann, als die günstigere Lösung. Solche Pumpen sind zwar in der Aquarientechnik als Bestandteile einer Filtereinrichtung schon lange bekannt und in Gebrauch, sie weisen aber nur eine geringe Förderhöhe auf, die für den geplanten $Z_{w e c k}$ vollkommen unzureichend war. Durch eine geeignete Umwandlung gelang es mir nun mit solch einfachen Pumpen, den erheblichen Niveauunterschied von etwa $80 \mathrm{~cm}$ zu überwinden. $\mathrm{Da}$ diese überaus einfache, dabei aber vollkommen betriebssichere Pumpe ohne Zweifel auch bei anderen Versuchsaufbauten Verwendung finden kann, erscheint mir eine kurze Beschreibung ihrer Konstruktion von allgemeinerem Interesse.

\section{DIE NEUE PUMPE}

In den üblichen Aquariumspumpen hebt man durch einen Luftstrom, der in das untere Ende des Heberohres geleitet wird, das Niveau des Wassers im Heberohr über 
den des umgebenden Wassers und treibt es in dieser Weise in den danebenstehenden Behälter, der etwa die gleiche Höhe hat. Der Nachteil dieser Anordnung besteht darin, daß die im Heberohr aufsteigende Luft-Wasser-Säule kein ausreichendes Widerlager an der unteren Offnung des Heberohres findet. Zumeist wird auch der Fehler gemacht, daß der Querschnitt des Heberohres zu groß gewählt wird, in der Absicht, eine möglichst hohe Pumpleistung zu erzielen. Hierdurch erreicht man aber nur, daß das von den Lufblasen angehobene Wasser zwischen den Luftblasen und der Rohrwandung wieder zurückfließt. Will man diesen Fehler vermeiden, so muß man den inneren

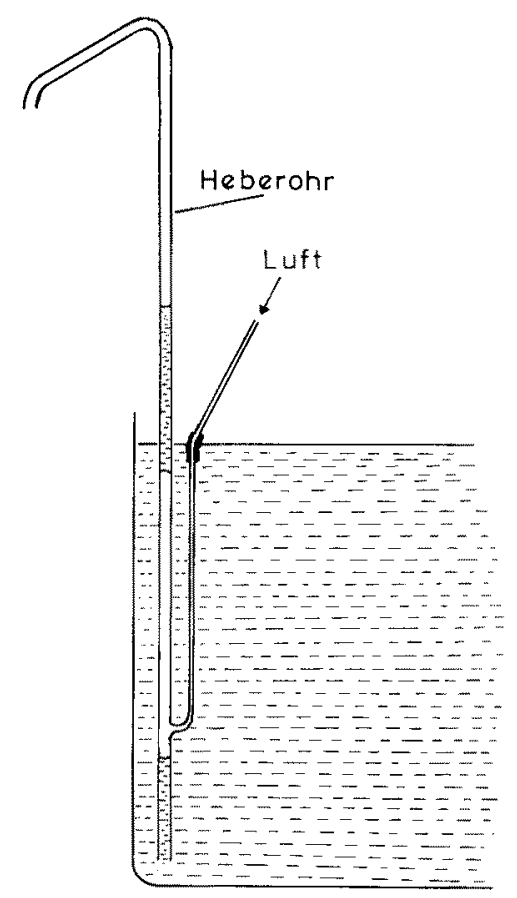

Fig. 1: Schematische Darstellung der Pumpe

Durchmesser des Heberohres so eng wählen, daß die aufsteigenden Luftblasen den Rohrquerschnitt vollkommen ausfüllen und die vor ihnen liegende Wassersäule geschlossen vor sich herschieben. Der maximale Querschnitt des Rohres, den man benutzen kann, beträgt nach meinen Erfahrungen etwa $5 \mathrm{~mm}$. Er kann auch enger gewählt werden, doch sinkt dann die Förderleistung der Pumpe.

Der zweite Gesichtspunkt, der bei der Konstruktion zu berücksichtigen ist, besteht darin, daß die Einströmungsöffnung für die Luft nicht am unteren Ende liegen darf, sondern in einigem Abstande davon, damit der beim Aufsteigen der Luft-Wasser-Säule entstehende Rückstoß durch die unterhalb der Lufteintrittsstelle liegende Wassersäule aufgefangen wird und daher am unteren. Ende des Heberohres keine Luftblasen austreten.

Praktisch arbeitet die Pumpe derart, daß der seitlich in das Heberohr eintretende 
Luftstrom die von dieser Stelle bis zum oberen Flüssigkeitsspiegel reichende Wassersäule abschneidet und diese dann durch die nachströmende Luft nach oben gedrückt wird, bis sie das obere Ende des Heberohres erreicht hat und dort abfließt. In diesem Augenblick füllt sich das Heberohr von neuem von unten her, es wird wieder die nachgeflossene Wassersäule abgeschnitten, und das Spiel beginnt von neuem.

Außer dem maximal zulässigen inneren Durchmesser, der etwas von der Benetzbarkeit des Materials beeinflußt wird, lassen sich bestimmte Abmessungen für die Pumpe nicht angeben, da sie von den gegebenen Verhältnissen abhängen; sie sind durch Probeversuche zu ermitteln. Verständlicherweise muß man die Einströmungsöffnung für die Luft möglichst tief legen, um eine gute Pumpleistung zu erzielen.

\section{ZUSAMMENFASSUNG}

1. Eine Modifikation der bekannten, mit Luft betriebenen Wasserpumpe wird beschrieben.

2. Ein geeigneter Rohrdurchmesser (etwa $5 \mathrm{~mm}$ ) und die Lage der Lufteintrittsöffnung oberhalb des unteren Rohrendes (Auffangen des Rückstoßeffektes) bewirken eine wesentliche Vergrößerung der Hubhöhe. 